\title{
La ideología en el Derecho y una sentencia uruguaya acerca del IVA*
}

\section{The ideology in law and an uruguayan court decision on value added tax (VAT)}

\author{
ANdrés JaVier Blanco**
}

\section{RESUMEN}

El análisis ideológico del discurso del Derecho es una de las vertientes más originales de la Teoria del Derecho en tanto apunta a conectar los contenidos de la legislación, la dogmática y la jurisprudencia con fenómenos sociales reales en términos funcionales. En el presente trabajo, luego de proponer un marco teórico del análisis ideológico, se presenta un caso real de la jurisprudencia uruguaya sobre el Impuesto al Valor Agregado (IVA), en el cual el análisis ideológico de la sentencia ilumina su sentido.

Palabras clave: ideologia, análisis ideológico, IVA.

\section{ABSTRACT}

The ideological analysis of the legal speech is one of the most original viewpoints of the legal general theory, since it directs to connect the contents of legislation, legal scholarships and adjudication with the social phenomena, in functional terms. In this article, after setting the theoretical basis of the ideological analysis, an Uruguayan court decision on Value Added Tax (VAT) is exposed and analyzed in ideological perspective, clarifying its meaning.

Keywords: ideology, ideological analysis, VAT.

*Artículo de investigación recibido el 15 de noviembre de 2017 y aceptado para publicación el 28 de febrero de 2018

** Profesor Investigador en la Facultad de Derecho de la Universidad de la República, Uruguay. (andresblanco@vera. com.uy) orcid.org/0000-0001-5824-6773 
SUMARIO: 1. Introducción / 2. Desarrollo del tema / 2.1 La ideología en general y en la teoría del derecho / 2.2 ¿De qué formas opera la ideología, en general y en el discurso del Derecho en particular? / 2.3 El uso de la ideología para la construcción de los hechos en el discurso jurídico: el caso de la sentencia del TCA sobre el IVA sobre el precio de los servicios notariales / 3. Conclusiones / 4. Bibliografía

\section{INTRODUCCIÓN}

La ideología es una de las ideas más fructíferas y a la vez más controversiales de las ciencias sociales. Sin perjuicio de que, como observaremos, hay una concepción débil de ideología que abarcaría prácticamente a todo sistema de creencias relativamente consistente. El atractivo radica en la versión (o versiones) fuerte de la ideología: sistemas de creencias que operan en forma velada, generalmente inconsciente, distorsionando aspectos de la vida social o creando justificaciones de conductas, con una función de conservar o alterar -según el caso- un grupo de relaciones sociales.

La Teoría del Derecho incorporó, desde diversas vertientes, dicha noción, con resultados, a mi juicio, excelentes en la explicación de ciertos aspectos del derecho como fenómeno social. En este trabajo propongo, en primer lugar, algunas nociones muy elementales y generales de qué se entiende por ideología en la epistemología de las Ciencias Sociales, y sus aplicaciones en la Teoría del Derecho en general. Seguidamente, se utilizarán algunas de estas aplicaciones para analizar una sentencia del Tribunal de lo Contencioso Administrativo (TCA) de Uruguay sobre el Impuesto al Valor Agregado (IVA).

Si bien asumo que los contenidos ideológicos están presentes en una gran parte -quizás en la mayoría- de los textos jurídicos, sean de Derecho Positivo, dogmáticos, jurisprudenciales, etc., la sentencia elegida tiene la ventaja de que su contenido ideológico es muy fácilmente identificable y analizable, mientras que en otros textos dicho contenido está más solapado o disimulado. A ello debe agregarse que en la sentencia confluyen no sólo argumentos (y contenidos ideológicos) específicamente del Derecho tributario con otros del Derecho privado, lo que permite apreciar con un sólo ejemplo la convergencia y semejanza de la ideología que divulga el discurso jurídico. 


\section{La ideología en general y en la Teoría del Derecho}

Si bien el concepto de ideología no nació con Marx y Engels, ${ }^{1}$ fueron ellos quienes la colocaron en el centro del análisis de los discursos sociales; o más ampliamente, impulsaron fuertemente la idea de que los discursos deben estudiarse como fenómenos sociales, al margen de que sean verdaderos o falsos, correctos o incorrectos. ${ }^{2}$ No obstante, a pesar de que el marxismo posterior a Marx y Engels continuó (y continúa) utilizando ampliamente a la ideología como categoría de análisis de los discursos, rápidamente ella fue aceptada, hasta hoy, por amplios sectores de la teoría social de filiación no marxista; tales son los casos - entre otros- de Mannheim, Kelsen y Van Dijk, que mencionaré en este trabajo.

Pero ¿qué es la ideología? Es usual decir que existe, por un lado, una concepción neutra del término, bajo la cual ideología se referiría a todo sistema de ideas acerca de la realidad social o de un sector de la misma. ${ }^{3}$ Esta noción neutra o amplia no deja de tener interés para el análisis de los lenguajes, ya que nos previene acerca de que un discurso cualquiera no es sólo lo que oímos o leemos directamente, sino que es un eslabón en una cadena de enunciados mucho más amplia, que contiene, entre otras cosas, creencias acerca de la sociedad y normas de muy diverso significado. A partir de esta noción amplia de ideología, advertimos que cualquier parte del discurso jurídico no supone solamente los hechos directamente enunciados en él ni el permiso, la prohibición o la obligación explícitamente manifestados, sino, por ejemplo, una creencia de que estableciendo esa prohibición, permiso u obligación se generará un efecto social que puede ser bueno para el que genera el texto pero no para el resto de la gente. En otras palabras, la noción amplia de ideología nos recuerda que, en contra de lo que se nos suele proponer desde una visión exegética ramplona, los juristas no operamos "solamente el Derecho", sino que estamos permanentemente asumiendo un compromiso con las visiones de la sociedad que subyacen a un texto positivo, dogmático o de una sentencia.

\footnotetext{
${ }^{1}$ Ya en el siglo XVII Francis Bacon, auténtico fundador de la Epistemología o Filosofía de la Ciencia, postuló que las personas tienen representaciones a las que llamó idola que refractan su entendimiento. Por otra parte, a principios del siglo XIX, Destutt de Tracy acuñó el término ideología para referirse al sistema completo de creencias que condiciona el conocimiento y la conducta. Véase Klimovsky, Gregorio e Hidalgo, Cecilia, La inexplicable sociedad. Problemas epistemológicos de las ciencias sociales, A-Z Editora, Buenos Aires, 1998, pp. 228-229.

${ }^{2}$ Marx, Karl y Engels, Friedrich, La ideología alemana, Pueblos Unidos, Montevideo, 1968, pp. 25 y ss.

${ }^{3}$ Courtis, Christian, "Detrás de la ley. Lineamientos de análisis ideológico del derecho", AA.W.: Observar la ley. Ensayos sobre metodología de la investigación jurídica (edición de Christian Courtis), Trotta, Madrid, 2006.
} 
Pero lo más interesante desde el punto de vista tanto teórico como epistemológico es lo que a veces se denomina como la versión fuerte del vocablo ideología: más allá de las variantes, para otro grupo de autores la ideología es un discurso que presenta una visión de la realidad, más especialmente de la vida social, o de un sector de ella, "que favorece los intereses de ciertos grupos sociales, y/o un cierto estado de cosas en la vida social". ${ }^{4}$ Esa presentación de la vida social o de un sector de la misma, de un modo sesgado por intereses sociales, tiene las siguientes características: a) en primer lugar, la ideología se presenta a sí misma como un discurso neutral u objetivo (cuando en realidad es todo lo contrario), por lo que su vinculación con los intereses de un grupo social o un estado de cosas permanece oculto o subyacente; b) en segundo lugar, la ideología es funcional a esos intereses o estructuras con los que se articula, presentando las relaciones sociales que se defienden como algo dado e inevitable, y/o rechazando a priori toda crítica que apunte a demostrar que las cosas pueden ser de otra forma; y c) en tercer lugar, la ideología se desenvuelve en su mayor parte en forma inconsciente, es decir, no es -como a veces sostiene en contra de su empleo como categoría de análisis- el fruto de una conspiración, sino de un proceso social espontáneo. ${ }^{5}$

La Teoría del Derecho ha sido un campo en el que la noción de ideología ha sido ampliamente utilizada para explicar el fenómeno jurídico como hecho social, si bien con variantes en cuanto a su significado y efectos. Por una parte, podemos identificar un sector de la Teoría del Derecho alineado con la concepción más fuerte de ideología, que incluye a quienes trabajan con marcos teóricos marxistas o cercanos al marxismo, ${ }^{6}$ así como también a Kelsen, ${ }^{7}$ que sin ser marxista adoptó una acepción de ideología muy cercana a la del marxismo. Otros autores, por su parte, analizan el Derecho como el producto de ideología pero entendido este término en su acepción amplia o neutra. Un caso aparte es el de Duncan Kennedy, que comentaré por separado.

\footnotetext{
${ }^{4}$ A las referencias a Marx y Engels ya realizadas, asi como a los teóricos del Derecho que se mencionarán, debe agregarse como referente de esta concepción fuerte de ideología: Mannheim, Karl, Ideología y utopía. Una introducción a la sociología del conocimiento, FCE, México, 2004, pp. 90-91; Hirst, Paul, On law and ideology, MacMillan, Londres y Basingstoke, 1979, pp. 23-27; Eagleton, Terry, Ideología. Una introducción, Paidós, Barcelona, 1997, pp. 24 y ss.

${ }^{5}$ Mannheim, Karl, Ideología y utopía..., pp. 72-73.

${ }^{6}$ Por ejemplo, Pašukanis, Evgeni, Teoría general del derecho y marxismo, Labor, Barcelona, 1976, pp. 61 y ss; Miaille, Michel, Une introduction critique au Droit, Francçois Maspero, Paris, 1977, pp. 110-112; Correas, Óscar, Crítica de la ideología jurídica, Centro de Investigaciones Interdisciplinarias en Ciencias y Humanidades (UNAM)-Coyoacán, México.

${ }^{7}$ Kelsen, Hans, Teoría pura del derecho, Porrúa, México, 1997, pp. 138-147.
} 
Para entender el uso de la ideología como categoría de análisis del Derecho, detengámonos justamente en la referencia de Kelsen que realicé en el párrafo anterior, en la cual este autor explica el concepto de derecho real. La acepción de derecho real como relación con la cosa es evidentemente falsa, puesto que toda relación jurídica es una relación social que vincula unas personas con otras. Pero nos dice Kelsen que la presentación falsa de una relación social como trabada con cosas y no con personas, como realmente ocurre, no es una simple falsedad ni tampoco es inocente, sino que cuando el Derecho Positivo o la dogmática hablan de esa forma, están presentando a la propiedad privada como algo preexistente a las personas. De esa forma, la propiedad privada pasa a imaginarse como algo impersonal e intemporal, lo cual la apuntala como institución social. En otras palabras, según Kelsen, la idea de derecho real como algo diferente a un permiso o una prohibición común constituye un discurso que veladamente legitima la propiedad privada atribuyéndole propiedades que, de hecho, no tiene.

En el campo tributario, se ha sostenido en Uruguay $^{8}$ que el artículo 10 del Código Tributario tiene un contenido ideológico cuando nos dice que el tributo existe para que el Estado obtenga recursos para cumplir con sus fines. ¿Por qué? Primero, la adición de esa referencia a la definición de tributo es innecesaria porque todo el resto del Código Tributario, así como la dogmática y la jurisprudencia, se desentienden por completo del tema del cumplimiento de los fines del Estado para resolver el resto de los problemas jurídicos del tributo: Todas estas cuestiones se deciden sólo alrededor de la exacción de dinero de los particulares por parte del Estado, siendo poco o nada relevante hacia dónde se destinen los recursos. Ciertamente, en Europa continental y América Latina algún sector dogmático hace cuestión del destino para deslindar subcategorías de tributos (como la tasa), pero la importancia recaudatoria de esos tributos es casi nula. Por lo demás, esas discusiones son relevantes para establecer subdivisiones del tributo pero no para delimitar el tributo como gran categoría de ingreso público. Por otro lado, desde el punto de vista social, y dependiendo del tipo de explicación teórica de la economía que se adopte, el tributo puede tener una función de regulación de la masa monetaria, como forma de estabilizar el sistema de precios y no de acercar recursos a la financiación de los gastos públicos. Por último, aun cuando se admitiera que el tributo alimenta de recursos al Estado para que éste gaste, fines del

\footnotetext{
${ }^{8}$ Blanco, Andrés, Estudios críticos sobre finanzas públicas y derecho tributario, FCU, Montevideo, 2013, pp. 29-33.
} 
Estado es un nombre que puede abarcar cualquier cosa que haga el Estado, desde alimentar a los indigentes hasta construir un arma de destrucción masiva. En suma, objetivamente parece que no hay motivos jurídicos ni de otra índole para que la definición legal de tributo nos diga que existe "para cumplir con los fines del Estado".

Ahora bien, la dogmática jurídica, en especial la del Derecho Público, cuando se refiere a los fines del Estado, casi siempre lo hace en términos aprobatorios o, a lo sumo, neutros. Si se lee cualquier manual de Derecho Público o incluso textos positivos que tratan del tema, no suele incluirse ninguna mención a actividades que todos los Estados, sin excepción, llevan a cabo y que estarían expuestas a juicios morales adversos. Es más, esa descripción laudatoria de las actividades del Estado suele incluirse en el aprendizaje institucional de niños y adolescentes, que normalmente incorporan tempranamente una visión positiva acerca de qué es y qué hace esa institución. Por eso, la alusión a los fines del Estado rodea al tributo de connotaciones positivas que lo legitiman como relación social, aunque descriptivamente no tengan mayor necesidad ni asidero.

El análisis del Derecho como portador de ideologías en el sentido que usualmente se usa en las ciencias sociales debe distinguirse del sentido que le otorga Kennedy al mismo vocablo. ${ }^{9}$ Para Kennedy, las ideologías jurídicas son grandes programas de política jurídica, obviamente vinculados con programas de política en general, que se utilizan para varios fines, como componer argumentos para resolver casos en contra del derecho positivo, interpretar términos susceptibles de varios significados en su uso corriente, etc. Desde luego que no se trata de una noción contrapuesta a la tradicional acepción de ideología, y de hecho es muy posible que los programas de los que habla Kennedy se alimenten de las ideologías entendidas al modo tradicional. La diferencia radica en que normalmente estos discursos de carácter político, cuando afloran (porque frecuentemente operan en forma subyacente, al igual que las ideologías entendidas al estilo clásico), no ocultan su uso normativo; contrario a las ideologías en sentido propio, que pretenden ser descripciones neutrales, los programas de política jurídica son abiertamente prescriptivos.

Existen dos prevenciones para el uso de la categoría ideología en el análisis de los discursos. La primera es la llamada Paradoja de Mannheim, por haber sido propuesta por este autor: si los intereses penetran los discursos y

\footnotetext{
${ }^{9}$ Kennedy, Duncan, A critique of adjudication, Harvard University Press, Cambridge (Massachusetts), 1997, p. 157 y ss.
} 
los convierten en ideologías, ¿por qué no suponer que la crítica a la ideología sea, a su vez, otra ideología? Realmente no existe una buena solución a esta paradoja pero, como indica Courtis, la fertilidad del concepto de ideología para el análisis de los lenguajes es tal que vale la pena asumir el riesgo de asumirlo sin tener resuelta la Paradoja de Mannheim. ${ }^{10}$

La segunda prevención es el abuso de la calificación ideológica de los discursos, en especial en el Derecho. En efecto, aunque entiendo que en porciones muy amplias, que además son probablemente las más importantes del Derecho positivo, la dogmática y la jurisprudencia tienen contenidos ideológicos, es evidente que ciertas porciones del Derecho no los tienen; ejemplos obvios son las normas sobre tránsito. ${ }^{11}$ Por otro lado, la existencia de contenidos ideológicos en textos jurídicos no implica que esos mismos textos carezcan, simultáneamente, de otros contenidos. En especial, la postulación de que el Derecho es portador de ideologías no descarta su función específicamente normativa, si bien, como veremos en el capítulo siguiente, la función ideológica de un texto lleva ínsita una pretensión normativa en tanto apunta a determinar conductas.

\section{3. ¿DE quÉ formas opera la ideOlOgía en general y EN El DISCURSO Del Derecho en particular?}

Pasando a un análisis más concreto de la forma en que opera la ideología, tenemos que señalar que ella incide primeramente en la comprensión de cada evento. Cuando un sujeto se enfrenta a una situación de la vida social, la ubica en un contexto más amplio de comprensión, que fue determinado, en parte, por una ideología. En virtud de esa ubicación del evento en un conjunto de representaciones creado - entre otros discursos- por la ideología, el sujeto llega a configurar el evento. Sólo de esta forma un hecho de la vida social significa algo. ${ }^{12}$ Aclaremos esto con un ejemplo.

Un sujeto se enfrenta a la situación de liquidar y pagar un tributo. Por un lado, es muy probable que califique a ese hecho como algo desagradable e intrínsecamente injusto. Ello ocurre porque esa persona ha asimilado el discurso ideológico que, según Kelsen, acompaña a la proposición de la

\footnotetext{
${ }^{10}$ Courtis, Christian, "Detrás del derecho...", op. cit., p. 354.

${ }^{11}$ Ibidem, pp. 352-353.

${ }^{12}$ Van Dijk, Teun, "Ideología y análisis del discurso", Utopía y praxis latinoamericana, Universidad de Zulia, Maracaibo, año 10, núm. 29, 2005, pp. 15-17.
} 
propiedad privada como un "derecho" sobre la cosa, por ejemplo, el dinero. Esa ideología ha creado un contexto en el cual los sujetos consideran que la propiedad es un hecho natural, previo e inderogable, por lo que cualquier situación que signifique lesionarla está cargado de valoraciones negativas. Por otro lado, quizá ese sujeto piense que ese pago contribuirá a que el Estado realice acciones positivas, como educar niños o asistir enfermos. Esto último también sucede porque el pago de tributos está inserto en un contexto de matriz ideológica en el cual se presenta al Estado como realizador de acciones buenas. De manera que, en virtud de la acción de una o más proposiciones ideológicas, queda conformado e inserto en la vida social e individual un hecho como el pago de un impuesto. El ejemplo es bueno para poner de manifiesto que, de la misma forma que en la vida social material, pugnan intereses contrapuestos; ello tiene también reflejo en las ideologías y las representaciones que ellas causan: la convivencia de intereses opuestos genera ideologías contrapuestas, y consecuentemente representaciones contrapuestas, a veces en la misma persona. Al pasar, digamos que esta convivencia de ideologías opuestas en discursos jurídicos referidos a una misma situación es un fenómeno que muchos autores han propuesto como típico del Derecho de los países capitalistas, tal es el caso de Balkin con su tesis acerca de la convivencia y conflicto permanente entre las visiones individualista y comunalista de la sociedad y el Derecho. ${ }^{13}$

En el ejemplo que mencioné, la construcción del evento y del contexto se producen en el nivel del sujeto convocado a cumplir lo que manda el Derecho; allí la ideología operaría en el campo que podríamos llamar cumplimiento espontáneo del Derecho, pero es evidente que hay otros ámbitos en los que la ideología opera muy activamente.

Uno de esos campos es la Dogmática. De la misma manera que el Derecho Positivo construye hechos a partir de ideologías y que, a partir de esos hechos o hacia ellos, construye sus mandatos, la Dogmática propone argumentos y soluciones a partir de hechos y contextos que aparentemente son descriptivos pero que a poco que se observa cómo develan ideologías subyacentes. Ilustremos esta afirmación con otro análisis en clave ideológica hecho por Kelsen. ${ }^{14}$ La separación dogmática entre derecho público y derecho privado dice fundarse en propiedades diferentes de la actividad del Estado y la ac-

\footnotetext{
${ }^{13}$ Balkin, Jack, "The crystalline structure of legal thought", Rutgers Law Review, vol. 39, núm. 1, 1986, pp. 11 y ss. Disponible en: http://digitalcommons.law.yale.edu/cgi/viewcontent.cgi?article=1293\&tcontext=fss_papers.

${ }^{14}$ Kelsen, Hans, Teoría pura..., op. cit., p. 287-289.
} 
tividad de los particulares. Sin embargo, sostiene Kelsen, objetivamente la diferencia es falsa puesto que todo el Derecho, sin importar el tipo de actos a los que se refiera, tiene la misma estructura y función: establece permisos y prohibiciones, y materializa estas últimas como sanciones a la conducta prohibida. La separación dogmática entre derecho público y derecho privado, sin embargo, no es simplemente un error, sino que responde al menos a dos concepciones ideológicas: puede encubrir la idea, enraizada con el liberalismo económico, de que el Estado no debe inmiscuirse en la vida económica, que se supone reservada a los particulares, o también la idea de que el Estado no debe tener demasiados frenos en su acción en el entendido de que "defiende el interés público".

Otra área del Derecho en donde opera la ideología es el de la práctica judicial, tanto por las partes en el proceso como por los jueces. Cuando una parte presenta un caso o se defiende, muy probablemente lo haga según el procedimiento que se observó al inicio de este capítulo: no como un hecho desnudo, sino como un evento calificado y ubicado en un contexto, delimitados ambos por discursos ideológicos. Esta práctica es la que observaremos en la sentencia que se comentará en el apartado 2.3. Desde luego que la construcción de argumentos para resolver un caso, sea por las partes o el mismo tribunal, puede estar llena de contenidos ideológicos directos o de premisas elaboradas a partir de ideologías.

Existen al menos dos modalidades más en que opera la ideología, que interesan particularmente al Derecho. ${ }^{15}$ Por un lado, tiene un efecto implícito que podríamos llamar normativo: una conducta se reproduce mejor si una ideología nos dice que "forma parte de la naturaleza" o es "necesaria". Por otro lado, al dotar a un hecho social de la propiedad de ser algo dado, intemporal y neutral, se legitima la estructura social: ésta deja de ser un fruto histórico mudable, y pasa a ser un estado de cosas invariable.

Seguidamente, se expondrá una sentencia de un tribunal uruguayo, en la que se puede observar en toda su intensidad el despliegue de más de una de estas funciones del discurso ideológico.

${ }^{15}$ Ricœur, Paul, Ideología y utopía, Gedisa, Barcelona, 2006, pp. 214 y ss. 
1.1 El uso de la ideología para la construcción de los hechos en el discurso jurídico: el caso de la sentencia del TCA sobre el IVA sobre el precio de los servicios notariales

La sentencia 424/2012 del Tribunal de lo Contencioso Administrativo (TCA) uruguayo ofrece un excelente ejemplo de uso de la ideología en la construcción de argumentos para la justificación de un acto particular de ejercicio del poder.

En síntesis, la Dirección General Impositiva (DGI) detectó que un notario público, en un período dado, había participado en la celebración de varias escrituras, no facturando precio alguno por ninguna de ellas, y por lo tanto no declarando ni abonando suma alguna por concepto de Impuesto al Valor Agregado (IVA). ${ }^{16}$ Por ese motivo, la DGI realizó un procedimiento de inspección que culminó con un acto administrativo en el cual determinó una deuda por concepto de IVA, además de sanciones. La DGI no halló evidencias del pago de precios por los servicios, por lo que estimó la deuda con base en las escalas recomendadas por la asociación gremial de notarios, como guía para la fijación de honorarios.

El notario a quien se determinó la deuda impugnó la resolución en vía administrativa y luego demandó su nulidad ante el Tribunal de lo Contencioso Administrativo (TCA), sosteniendo que realmente no había percibido precio alguno por sus servicios, dado que todos los destinatarios de los mismos eran familiares y amigos. Además de alegar directamente esta circunstancia, el notario tradujo al discurso jurídico esa alegación como una "falta de prueba" y "falta de motivación" del acto administrativo.

El TCA en su sentencia rechazó las defensas del notario y ratificó la determinación de deudas hecha por la DGI, sosteniendo que para servicios de esta naturaleza hay que "presumir" la onerosidad. En otras palabras, sin mediar evidencias, para el TCA el simple hecho de tener una actividad profesional supone que se están percibiendo precios, por lo que como regla es falso todo enunciado que sostenga que esa actividad se cumple en forma gratuita. El TCA invoca, además, varios textos del Código Civil y del Código de Comercio, en los que se establece que, en ausencia de pacto expreso sobre la retribución de los prestadores de servicios, estos pueden igualmente reclamarlo al prestatario, fijándose en tal caso según los usos del mercado. Tan fuerte es esa

\footnotetext{
${ }^{16}$ No se incluyó en la determinación ningún impuesto a la renta puesto que en Uruguay, en el período en que se produjeron los hechos (1998-2005), ningún impuesto de ese tipo gravaba los ingresos de profesionales como los notarios públicos.
} 
presunción sostenida por el TCA que el tribunal desecha los documentos y las declaraciones de testigos ofrecidos por el notario, que corroboraban que los servicios se habían prestado en forma gratuita.

Debo decir que el TCA utilizó un argumento que rebasa esa presunción presentada en su forma pura y dura. En efecto, el TCA hace también una inducción: dado que los servicios eran en su mayoría escrituras de compraventas de inmuebles, si los prestatarios tenían dinero para comprar inmuebles, es difícil creer que no tuvieran dinero para pagar el precio del servicio de un notario. De todas formas, esta inducción sólo controvierte la gratuidad de los casos en que la amistad se unía a la alegación de supuestas "dificultades económicas" para pagar el precio de los servicios del notario, pero no a los casos en los que el notario sostuvo que no percibió honorarios por la simple relación familiar o amistosa con la parte de la compraventa.

Pues bien, la "presunción de onerosidad" que utiliza el TCA para resolver el caso está directamente tomada de discursos ideológicos. En efecto, esa presunción es una continuación de la idea de que todas las conductas individuales están regidas pura y exclusivamente por la evaluación de la utilidad adicional que reporta o no un acto, y que esa utilidad tiene como única medida el beneficio económico, medido en dinero. Este es el núcleo duro de la corriente económica neoclásica, con su concepto de utilidad marginal, ${ }^{17}$ especialmente en la formulación que terminó por eliminar todo posible contenido moral o no dinerario de la utilidad como motivación de la conducta. ${ }^{18}$ Esta visión es ideológica, ya que, como lo ha señalado Sen, las motivaciones de la conducta de las personas, inclusive en sus relaciones de intercambio económico, son mucho más vastas que el deseo de una mayor cantidad de dinero. Por ejemplo, y esto hace especialmente al caso que resolvió el TCA, Sen señala que son muchos y muy frecuentes los casos en los que las personas actúan económicamente por motivaciones que el autor llama de agencia, esto es, por atribuir al acto que se realiza un valor basado en creencias de diversa índole (religiosas, morales, políticas, etc.), diferentes a la obtención de una suma de dinero adicional. Por lo tanto, la terquedad de la teoría de la utilidad marginal en reducir todas las motivaciones al "egoísmo económico"

\footnotetext{
17 Jevons, William Stanley; Jevons, William Stanley, The Theory of Political Economy, 1914, pp. 27-74. Disponible en: http://socserv2.socsci.mcmaster.ca/econ/ugcm/3\|3/jevons/TheoryPoliticalEconomy.pdf; Marshall, Alfred, Principios de economía, Aguilar, Madrid, 1944, pp. 81-82.

${ }^{18}$ Stigler, George, "Economics or ethics?", The Tanner Lectures on Human Values, 1980, pp. 148-150. Disponible en: http://tannerlectures.utah.edu/_documents/a-to-z/s/stigler81.pdf.
} 
proporciona una visión falsa del funcionamiento social. ${ }^{19}$ Sin llamarla de esa forma, las observaciones de Sen implican que, en sus versiones duras, la teoría de la utilidad marginal es una ideología: propone una reducción monista de la conducta humana, descalificando todas las otras motivaciones de la misma. Ese monismo absolutiza las motivaciones que son típicas en las economías mercantiles, y en especial en el capitalismo, que realmente están centrados en la obtención de dinero por cada intercambio. De esta manera, implícitamente se divulga la creencia en que esa "forma de actuar mercantil" es eterna e ineluctable.

Si comparamos la discusión anterior con la "presunción de onerosidad" que maneja el TCA, queda en evidencia la comunidad de esta presunción con la ideología centrada en la utilidad individual como única motivación de la conducta. En efecto, el discurso que toma como punto de partida la máxima "nadie trabaja gratis" es ideológico: descarta, de principio, que las personas tengan motivaciones emocionales, filantrópicas, morales, religiosas o de cualquier otro tipo, que las lleven a trabajar gratis, incluso ocasionándose a sí mismas pérdidas económicas. Ciertamente que en la sociedad capitalista la motivación central para realizar una actividad productiva es tener más dinero, pero lo ideológico radica en presumir que, incluso a despecho de ciertas pruebas (como ocurrió en el caso), la gente es irremediablemente egoísta. Es en este punto precisamente donde una creencia se vuelve ideología: su sustracción a la crítica, la ceguera deliberada a las evidencias contrarias, el simple hecho de "asumir que", colocando el punto de partida del discurso en el supuesto que de antemano se toma por cierto y no el abordaje abierto de los hechos, todo eso es lo que conforma un discurso ideológico. Y eso es lo que hizo el TCA en su sentencia.

La ideología está en este caso operando en las maneras que propuse en el capítulo 3. Primeramente, hay un contexto pseudo-fáctico constituido por uno o más enunciados ideológicos ("nadie trabaja gratis" o "la única motivación posible es la persecución de un mayor ingreso monetario") que generan una premisa de un discurso de justificación de una sentencia ("la onerosidad se presume en las actividades de servicios profesionales"). De esta forma, no hay prueba de hechos, sino un enunciado apriorístico tomado acríticamente (por eso es ideológico) sin atender a evidencias por más que éstas sean cuestionables o escasas. Esos enunciados ideológicos filtran la única evidencia tomada

\footnotetext{
${ }^{19}$ Sen, Amartya, Sobre ética y economía, Alianza, Madrid, 1999, pp. 32 y ss.
} 
en cuenta (que el notario no había facturado ni había pagado impuestos), y el resultado de esa visión ideológica de una sola circunstancia es la que se compara con los textos normativos generales (en este caso, la ley del IVA).

En segundo lugar, el carácter público de la sentencia divulga la ideología en ella contenida: se reafirma la idea de que realmente no hay, salvo excepciones, conductas económicamente relevantes motivadas por impulsos diferentes a la obtención de un ingreso. Además, se disuade a los que quieran actuar de esa forma: si alguien piensa en trabajar gratis para los demás, puede esperar que la administración tributaria y un tribunal entiendan que esa gratuidad es falsa y terminen perjudicando a la persona determinándole un impuesto a la renta o el IVA. Por lo tanto, el que realmente piense trabajar gratis se expone a lo que, económicamente, es una posible represalia de parte de la autoridad pública.

Todo lo anterior no significa que la tesis de la DGI y el TCA no fuera cierta en el caso particular: es muy posible que el notario fiscalizado realmente percibiera precios por todos o varios de los trabajos que según él sólo hacía por "amistad" y que realmente omitiera facturar como parte del incumplimiento del pago del IVA. Pero eso no quita que el discurso del TCA haya sido ideológico en el sentido de que lo entiendo en este trabajo: en efecto, y apartándome en este punto de la definición de Marx y Engels en La ideología alemana, entiendo que la ideología no es necesariamente un discurso falso, sino un discurso asumido acríticamente y que se parapeta ante las críticas que vengan desde fuera, más allá de que en ciertos casos los enunciados ideológicos sean verdaderos en cuanto corresponden con hechos reales.

También, cabe decir que la afirmación de que el TCA utilizó una ideología para fundar su fallo no significa ninguna valoración ética de las personas que integran el tribunal. Como lo indiqué antes, las personas asumen y reproducen la ideología sin darse cuenta de ello y sin que tengan intenciones de conspirar ni mentir. El discurso ideológico es un campo en el que las personas viven desde que nacen, que asimilan durante todo su aprendizaje y del que se alimentan sus representaciones, al margen de sus voluntades. Esa es, por lo demás, la clave de la eficacia de la ideología: se presenta como lo obvio o lo asumido generalmente en la vida social, de manera que adoptar un enunciado ideológico, reproducirlo y convertirlo en otros enunciados es una parte absolutamente normal de la construcción de los discursos sociales, como en este caso el discurso jurídico. Con toda seguridad, yo mismo he reproducido discursos ideológicos. 
Un punto interesante es observar el grado de complejidad que tiene el discurso ideológico que utiliza el TCA. El pensamiento económico neoclásico es la versión sofisticada y académica de la visión ideológica de la sociedad en la que sólo el deseo de ganancia mueve a las personas. Sin embargo, en la sentencia que comento, el TCA no utiliza el discurso académico de la economía neoclásica, sino una versión simplificada de la misma. Lo que ocurre es que la ideología va adoptando versiones más diluidas a medida que se aleja de sus centros de producción original, como instituciones académicas, centros de análisis, etc. Los enunciados ideológicos que utilizó el TCA en la sentencia a la que me refiero son de este último tipo: expresiones no fundamentadas, sin léxico teórico económico, sino ya transmutadas al lenguaje jurídico (presunción y onerosidad son palabras típicas de los juristas). La transmutación al léxico y estilo jurídicos es mucho más evidente cuando se acude a los enunciados, también cargados de ideología, del Código Civil y del Código de Comercio uruguayos.

Por ejemplo, el TCA, en su sentencia, transcribe el artículo 1834 del Código Civil uruguayo, del cual me interesa el siguiente párrafo:

El que hiciere algún trabajo o prestare algún servicio a otro puede demandar el precio, aunque ningún precio o retribución se hubiese ajustado, siempre que el tal servicio o trabajo fuese de su profesión o modo de vivir honesto. En este caso se presumirá que los interesados ajustaron el precio de costumbre para ser determinado judicialmente, si hubiere duda.

Este texto del Código Civil parte del mismo enunciado ideológico que el TCA. Palabra más, palabra menos, "nadie trabaja gratis ni por el simple gusto de beneficiar a otros”. De manera que el Código Civil establece una regla a partir de una visión de la sociedad en que la filantropía, la solidaridad, la amistad, los vínculos familiares, etc., son conductas excepcionales. Lo mismo que el $T C A$, al fundar un texto normativo en esa concepción ideológica, el Código Civil reafirma esta última.

Pero tanto la sentencia del TCA como el Código Civil uruguayo no tienen sólo el papel de divulgar la ideología, sino que en ellos ésta se convierte en un discurso específicamente normativo, ya que se determina la conducta de las personas en el sentido en que apunta la ideología. La ideología misma disuade la conducta no funcional, que en este caso sería desarrollar una actividad en forma gratuita. Además, el discurso jurídico se apropia de las 
descripciones ideológicas de las conductas para establecer posibles actos de coacción contra el que se desvíe del modelo que suministró la ideología: la persona que crea que le están haciendo un favor al recibir gratuitamente un servicio profesional puede despertar un día con una demanda reclamando un precio no pactado expresamente, y el que trabaja por simple altruismo o amistad puede despertar otro día con una determinación de impuestos sobre un precio que no percibió.

\section{Conclusiones}

El caso reseñado en el apartado 2.3 confirma la hipótesis general propuesta por quienes afirman que el discurso jurídico tiene contenidos ideológicos, además de los específicamente normativos. En particular, el ejemplo confirma que la ideología es conformadora -entre otras cosas- del evento, que en la práctica judicial equivale a los hechos en los que dice basarse el juez para ordenar a alguien una cierta conducta. Esta conformación no fue, en el caso, meramente auxiliar, sino que la totalidad del hecho es presupuesta a partir de premisas ideológicas.

Por otro lado, también se confirma la función indirectamente normativa que tiene la ideología al sancionar las conductas que se desvíen del patrón funcional para el sistema económico, inclusive si -como en este caso- probablemente el desvío no era real, sino simplemente discursivo, como parte de una estrategia de defensa en juicio.

\section{Bibliografía}

Balkin, Jack, "The crystalline structure of legal thought", Rutgers Law Review, vol. 39, núm. 1, 1986. Disponible en: http://digitalcommons.law.yale.edu/cgi/ viewcontent.cgi? article $=1293$ Ctcontext=fss_papers.

Blanco, Andrés, Estudios criticos sobre finanzas públicas y derecho tributario, FCU, Montevideo, 2013.

Correas, Óscar, Critica de la ideología jurídica, Centro de Investigaciones Interdisciplinarias en Ciencias y Humanidades-UNAM/Coyoacán, México, 2005.

Courtis, Christian, “Detrás de la ley. Lineamientos de análisis ideológico del derecho", Observar la ley. Ensayos sobre metodología de la investigación jurídica (Edición de Christian Courtis), Trotta, Madrid, 2006.

Eagleton, Terry, Ideología. Una introducción, Paidós, Barcelona, 1997.

Hirst, Paul, On law and ideology, MacMillan, Londres y Basingstoke, 1979. 
Jevons, William Stanley, The Theory of Political Economy, 1994. Disponible en: http://socserv2.socsci.mcmaster.ca/econ/ugcm/3ll3/jevons/TheoryPoliticalEconomy.pdf.

Kelsen, Hans, Teoría pura del derecho, Porrúa, México, 1997.

Kennedy, Duncan, A critique of adjudication, Harvard University Press, Cambridge (Massachusetts), 1997.

Klimovsky, Gregorio e Hidalgo, Cecilia, La inexplicable sociedad. Problemas epistemológicos de las ciencias sociales, A-Z Editora, Buenos Aires, 1998.

Marshall, Alfred, Principios de economía, Aguilar, Madrid, 1944.

Marx, Karl y Engels, Friedrich, La ideología alemana, Pueblos Unidos, Montevideo, 1968.

Miaille, Michel, Une introduction critique au Droit, Francçois Maspero, París, 1977. Pašukanis, Evgeni, Teoría general del derecho y marxismo, Labor, Barcelona, 1976.

Ricœur, Paul, Ideología y utopía, Gedisa, Barcelona, 2006

Sen, Amartya, Sobre Ética y Economía, Alianza, Madrid, 1999.

Stigler, George, "Economics or ethics?", The Tanner Lectures on Human Values, 1980. Disponible en: http://tannerlectures.utah.edu/_documents/a-toz/s/stigler81.pdf.

Van Dijk, Teun, “Ideología y análisis del discurso", Utopía y Praxis Latinoamericana, Universidad de Zulía, Maracaibo, año 10, núm. 29, 2005, 